\title{
Correlation between surface crack width and steel corrosion in reinforced concrete
}

\author{
Michele Win Tai Mak ${ }^{1, \star}$, Pieter Desnerck ${ }^{2}$, and Janet M. Lees ${ }^{1}$ \\ ${ }^{1}$ Department of Engineering, University of Cambridge, Trumpington St, Cambridge CB2 1PZ, United Kingdom \\ ${ }^{2}$ Department of Civil and Environmental Engineering, Brunel University London, Uxbridge, UB8 3PH, United Kingdom
}

\begin{abstract}
Reinforced concrete structures are subjected to weather conditions, chemical attack and other sources of deterioration that can affect their performance. In particular, corrosion of the internal steel reinforcement is considered to be one of the main causes of structural deterioration. A possible consequence of corrosion is cracking of the surrounding concrete.

Visual inspections are often used to inform asset management strategies. Finding a relationship between cracks that are visible on the outer surface of a structure and corrosion of the internal reinforcement can be helpful when making assessment decisions. To this end, unconfined cylindrical concrete specimens with an embedded steel bar have been subjected to accelerated corrosion using an impressed current density of $200 \mu \mathrm{A} / \mathrm{cm}^{2}$, leading to steel mass losses between 5-24\%. This paper discusses the measured correlation between corrosion-induced surface crack widths and degree of reinforcement corrosion. The tests highlighted some limitations of a set-up that is commonly adopted for accelerated corrosion and concentric pull-out bond testing. The findings of this study represent a first step towards the standardisation of accelerated corrosion testing procedures using an impressed current.
\end{abstract}

\section{Introduction}

The deterioration of reinforced concrete infrastructures represents a significant problem that leads to high costs for asset managers [1-3].

Reinforced concrete structures are subjected to weather conditions, chemical attack and other sources of deterioration that can reduce their load-bearing capacity. In particular, corrosion of the internal steel reinforcement is widely considered to be one of the most critical deterioration mechanisms in reinforced concrete structures [2-11].

Corrosion affects the overall structural capacity in different ways. It can lead to a reduction of the cross section of a steel bar, directly reducing the maximum tensile force that the bar can resist. Corrosion products can weaken the interface between steel and concrete by reducing the cohesion and friction between the two materials. As corrosion products occupy a greater volume than the parent metal, they develop expansive pressures. For very low levels of corrosion this may enhance the bond strength, but at higher levels it can lead to cracking of the surrounding concrete. After cracking, concrete hoop stresses cannot fully develop to balance the radial components of the compressive cones, which are the main resisting mechanism of bond. As the cracks open, the contact area between concrete lugs and steel ribs is reduced, further reducing the capacity of the compressive cones developed in the concrete. As a result, a degradation of composite action and reinforcement anchorage can occur, causing a reduction of the overall struc-

\footnotetext{
${ }^{\star}$ Corresponding author: mwtm2@cam.ac.uk
}

tural capacity. A comprehensive overview of the effects of reinforcement corrosion is given in fib Bulletin 10 [12].

Corrosion cannot be easily detected during inspections on existing structures that are in service and their consequences are hard to quantify. To this end, non-destructive testing (NDT) techniques are often adopted at different stages in asset management strategies, where visual assessments are often the first step. However, correlating measurable parameters on the concrete surface (e.g. crack widths) and deterioration processes hidden inside the structure (e.g. level of reinforcement corrosion) is a major challenge.

Several authors [3, 9, 13,-19] have studied corrosioninduced cracking of concrete, either focusing on the process that leads to the onset of cracking, or the correlation between surface crack width and level of internal corrosion.

Based on experimental results (either with impressed current techniques or controlled exposure to chlorides), different empirical models have been proposed to correlate the corrosion penetration and crack widths. Some authors [13, 16-18] propose a linear relationship between the surface crack width and the degree of corrosion after the onset of cracking, with factors and additive coefficients based on empirical data. Others [15, 19] use nonlinear relationships proposing formulations with exponents less than unity and other empirical factors. Other authors [3] propose more complex formulations to take into account the relative distance and position between cracks.

A study by Bossio et al [3] comparing predictive models with experimental results shows that there is little agreement between the existing models. This could be partially 
attributed to the different testing conditions, as the nature of the corrosion product can vary significantly [9].

The objective of the research presented in this paper is to study the correlation between corrosion-induced surface crack widths and degree of corrosion in the internal reinforcement. Experiments were carried out on reinforced concrete cylinders where corrosion was generated using an impressed current. The effects of the boundary conditions of the corroded length within the specimens are also investigated.

\section{Accelerated Corrosion}

Corrosion can be studied under natural conditions or in a controlled environment through laboratory experiments. In the latter case the corrosion process is often accelerated using an impressed current technique to reduce the duration of the experiments. An external current is applied to the specimens, and the induced flow of electrons causes the corrosion of the steel.

This method has been used extensively in the past. Faraday's law of electrolysis [4, 20], shown in Equation 1. is often used to calculate the approximate time required to develop different levels of corrosion:

$$
\Delta m_{F}=\frac{I \cdot t \cdot M}{F \cdot z}=\frac{I \cdot t \cdot 55.845}{96,487 \cdot 2}
$$

where:

$\Delta m_{F}$ theoretical mass loss $[\mathrm{g}]$

$I$ current intensity [A]

$t$ time $[\mathrm{s}]$

$M$ atomic weight of metal $(55.845 \mathrm{~g} / \mathrm{mol}$ for $\mathrm{Fe})$

F Faraday's constant $(96,487 \mathrm{C} / \mathrm{mol})$

$z$ ionic charge

The current density $i_{\text {corr }}$ is a key parameter in the corrosion process [4, 12, 14, 20], and is defined as the average current intensity $I$ involved in the electrochemical process divided by the steel surface area exposed to corrosion $A_{r}$ :

$$
i_{\text {corr }}=\frac{I}{A_{r}}=\frac{I}{\pi \cdot \varnothing \cdot L}
$$

where the surface area of a bar exposed to corrosion is expressed as a function of the nominal diameter of the bar $\varnothing$ over the corroding length $L$.

In early accelerated corrosion tests using an impressed current, very high values of current density were used. Al-Sulaimani et al [21] are among the first authors to have studied the influence of corrosion and cracking on bond strength using an impressed current. They used a current density of $i_{\text {corr }}=2,000 \mu \mathrm{A} / \mathrm{cm}^{2}$. Almusallam et al [22] used an even higher impressed current density ${ }^{1}$ of

\footnotetext{
${ }^{1}$ Value not reported, calculated based on size and dimensions
}

$i_{\text {corr }}=10,400 \mu \mathrm{A} / \mathrm{cm}^{2}$. El Maaddawy and Soudki [4] carried out a systematic study to investigate the effects of different levels of impressed current. They measured the side strains on the concrete surface due to the expansion of corrosion products and concluded that higher current densities lead to increased side strains between $i_{\text {corr }}=100$ $500 \mu \mathrm{A} / \mathrm{cm}^{2}$ and recommended the use of values lower than $i_{\text {corr }}=200 \mu \mathrm{A} / \mathrm{cm}^{2}$.

\section{Experimental Programme}

The experimental programme investigated accelerated corrosion using an impressed current on a total of 40 cylindrical concrete specimens without transverse confining reinforcement. The crack widths were subsequently measured and compared with the average mass losses of the bars. The specimens were designed to reflect pull-out bond tests and this determined the geometry and characteristics of the specimens.

An overview of the specimen series and numbering system is given in Table 1. Target mass losses between 2-15\% were calculated using Faraday's law. In the numbering system, the last two digits of each series indicate the target mass losses as a percentage. For each value of target mass loss, five specimens (labelled $a$ to $e$ ) were tested under the same conditions to provide a statistically significant distribution of the results.

The specimens were partially submerged in a salt-water solution to diffuse the current. In Series A, all sides of the cylinders were left exposed to the salt-water bath. In Series $\mathrm{B}$, the bottom side of the cylinders was waterproofed with silicon sealant to avoid direct contact with the water. This allowed for a more homogeneously distributed current flow along the cylinders, without concentrations at the base of the specimen.

Table 1. Test matrix

\begin{tabular}{cc|cc}
\hline Series & $\begin{array}{c}\text { Serial } \\
\text { Nos. }\end{array}$ & $\begin{array}{c}\text { Theoretical } \\
\text { Mass Loss } \\
\mathrm{C}_{F}\end{array}$ & $\begin{array}{c}\text { Corrosion } \\
\text { time } \\
\text { [days] }\end{array}$ \\
\hline $\mathrm{A} 10-15$ & $1-5$ & $17.1 \%$ & 67.0 \\
$\mathrm{~A} 10-07$ & $6-10$ & $8.0 \%$ & 31.2 \\
$\mathrm{~A} 10-05$ & $11-15$ & $5.4 \%$ & 21.2 \\
$\mathrm{~A} 10-02$ & $16-20$ & $2.3 \%$ & 9.0 \\
\hline $\mathrm{B} 10-08$ & $21-25$ & $10.1 \%$ & 39.8 \\
$\mathrm{~B} 10-06$ & $26-30$ & $7.4 \%$ & 28.9 \\
$\mathrm{~B} 10-04$ & $31-35$ & $5.3 \%$ & 20.9 \\
$\mathrm{~B} 10-03$ & $36-40$ & $3.8 \%$ & 14.9 \\
\hline
\end{tabular}

\subsection{Specimen Geometry}

The specimens were concrete cylinders with a diameter of $107 \mathrm{~mm}$ and a height of $100 \mathrm{~mm}$. A ribbed steel bar with a nominal diameter $\varnothing=10 \mathrm{~mm}$ was cast concentrically in the cylinders. The nominal cover was $c=48.5 \mathrm{~mm}$ and the resulting cover-to-diameter ratio was 4.8 . The bond length was $l_{b}=5 \varnothing=50 \mathrm{~mm}$, based on RILEM [23] recommendations for pull-out tests. The geometry of the specimens is shown in Fig. 1 . 


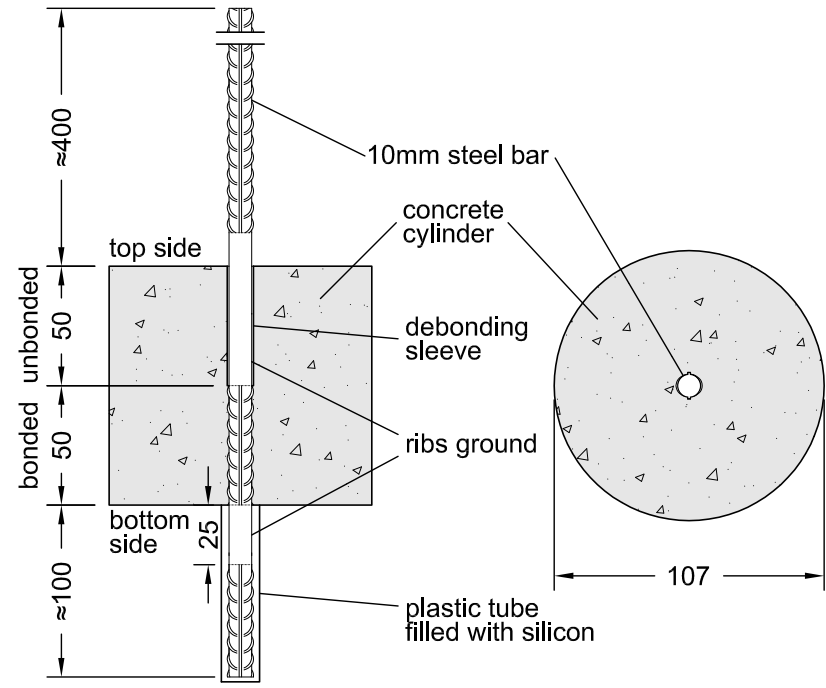

Figure 1. Specimen geometry: section along the longitudinal axis and transverse cross section through the concrete cylinder

A debonding sleeve was provided on the remaining $50 \mathrm{~mm}$ bar segment in the concrete and on the first outer $25 \mathrm{~mm}$ of the bar on the opposite side, measured from the concrete edge. The sleeve was obtained by removing the ribs with a belt sander and wrapping the bar with layers of electrical and masking tape. Fig. 2] shows the rib pattern on the bonded length, and the adjacent debonding sleeves.

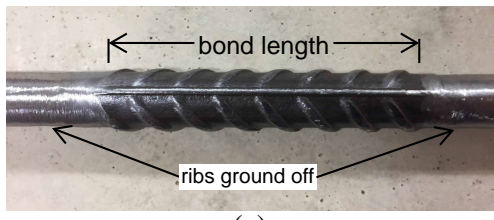

(a)

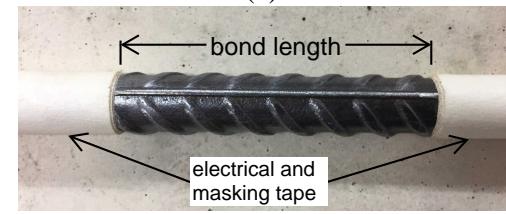

(b)

Figure 2. Debonding sleeves adjacent to bonded length $l_{b}=50 \mathrm{~mm}$ : (a) Ribs ground off; (b) Electrical and masking tape applied over unbonded segments

\subsection{Materials}

\subsubsection{Concrete}

The concrete mix and the proportions of constituents are summarised in Table 2. At 28 days after casting, material characterisation tests were carried out in accordance with EN 12390-3:2009 [24] and EN 12390-6:2009 [25]. The average 28 days concrete compressive strength $f_{c, \text { cub }}$ measured on $100 \mathrm{~mm}$ cubes was $32.0 \mathrm{MPa}$ for Series A and 31.0MPa for Series B.
Table 2. Concrete mix

\begin{tabular}{llcc}
\hline Constituent & Type & $\begin{array}{r}\text { Density } \\
{\left[\mathrm{kg} / \mathrm{m}^{3}\right]}\end{array}$ & $\begin{array}{c}\text { Amount } \\
{\left[\mathrm{kg} / \mathrm{m}^{3}\right]}\end{array}$ \\
\hline Water & - & 1,000 & 180 \\
Cement & CEM II-A-LL & 3,100 & 300 \\
& $32.5 \mathrm{R}$ & & \\
$\begin{array}{l}\text { Fine Aggregate } \\
\begin{array}{l}\text { Coarse Aggregate } \\
\text { (uncrushed) }\end{array}\end{array}$ & $\begin{array}{l}4 / 4 \mathrm{~mm} \\
\text { unc }\end{array}$ & 2,625 & 835 \\
\hline
\end{tabular}

\subsubsection{Steel reinforcement}

The reinforcement bars were made of high-strength hotrolled steel. The yield strength $f_{y}=530 \mathrm{MPa}$ and ultimate tensile strength $f_{u}=619 \mathrm{MPa}$ were obtained from uniaxial tensile tests.

Prior to grinding, the bars were weighed on an electronic scale with a capacity of $15.0 \mathrm{~kg}$ and a resolution of $0.2 \mathrm{~g}$. The measured mean weight per unit length of the bars was $g_{0}=611.3 \mathrm{~g} / \mathrm{m}$ with a Standard Deviation (SD) of $1.5 \mathrm{~g} / \mathrm{m}$. After the ribs were ground off along the unbonded length, the weight of the individual bars was also recorded.

\subsection{Mixing, Casting, Curing}

Fresh concrete was mixed and cast in two separate batches of 20 specimens. Polyvinyl chloride (PVC) pipes with an inner diameter of $107 \mathrm{~mm}$ were used as moulds for the cylinders. The moulds and reinforcement bars were held in position with a timber frame during casting. The longitudinal axis was oriented vertically with the bonded length on the upper part of the cylinders.

Specimens were cast and compacted on a vibrating table in two layers, and immediately covered with plastic sheets. Approximately 24 hours after casting, the specimens were removed from the timber frame, wrapped in plastic sheets (while kept inside the plastic moulds) and left to cure. The plastic sheets and moulds were removed after a standard curing period of 28 days.

\subsection{Accelerated Corrosion}

A current density of $200 \mu \mathrm{A} / \mathrm{cm}^{2}$ was used in the experiments. This is in line with the observation that very high currents can lead to non-representative effects and the recommendation that current densities lower than 200$250 \mu \mathrm{A} / \mathrm{cm}^{2}$ are most appropriate [4, 20, 26].

The specimens were submerged in a $5 \% \mathrm{NaCl}$ water solution in separate plastic boxes for at least 3 days before current was impressed to generate corrosion. The shorter protruding bar ends at the bottom of the cylinders were protected in plastic tubes and sealed with silicon. This was necessary to avoid direct contact between the steel bars and the chloride-rich water of the accelerated corrosion tests. Stainless steel plates were used as cathodes. During the experiments, the boxes were closed with a plastic lid. The test set-up is shown in Fig. 3 . 


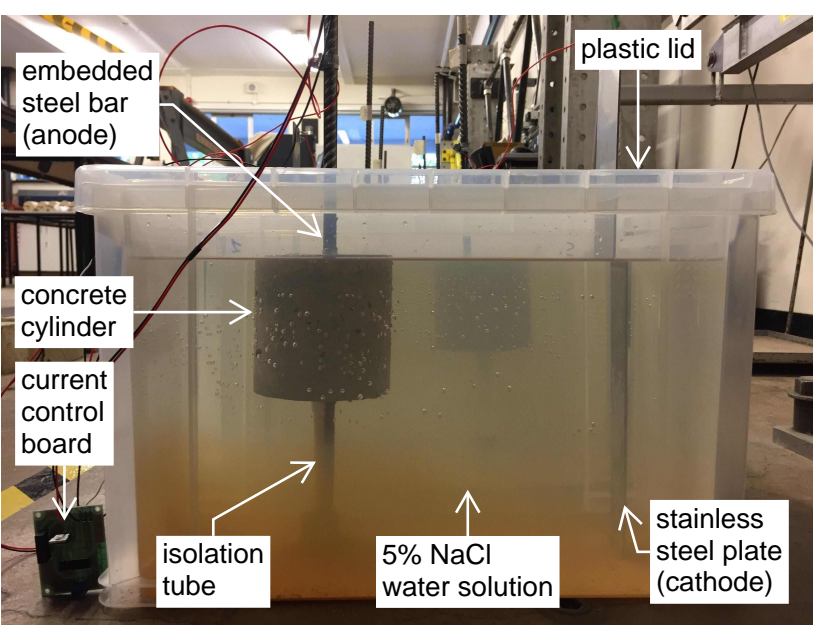

Figure 3. Photo of accelerated corrosion test set-up

Specimens with the same target corrosion levels were connected in series, to ensure that the same current was impressed. The different series, each corresponding to a given target mass loss, were connected in parallel. Power supplies with a maximum voltage of $32 \mathrm{~V}$ were used.

Current control boards were developed to control the current intensity to within $\pm 1 \%$.

The different series had to be kept under impressed current for different periods of time. Corrosion was therefore initiated on a different day for each series, but the tests were stopped approximately on the same day. This was desirable so that the concrete was of the same age (therefore approximately the same strength) for all the series at the end of the accelerated corrosion testing. This allowed for more reliable and consistent results.

\subsection{Crack width measurement}

At the calculated time the impressed current was interrupted, the specimens were removed from the salt-water bath and left to dry for at least one day. Surface crack widths were measured with an optical microscope with a magnification factor of 40x. As the crack widths were not uniform along the cylinders, only the maximum crack width values were used in the analysis of the results. In the case of multiple cracks, the maximum cumulative crack width $w_{c}$ was used, calculated as the sum of all crack width values along a directrix (a circumferential line at a given longitudinal coordinate $\xi$ ). The definition of cumulative crack width is indicated in Eq. 3 and the reference system used is shown in Fig. 4

$$
w_{c}=\max \left(\sum_{i=1}^{n} w_{i}\right)_{\xi}
$$

\subsection{Rust Removal}

At the end of the accelerated corrosion tests, the concrete cylinders were broken apart and the steel bars removed.

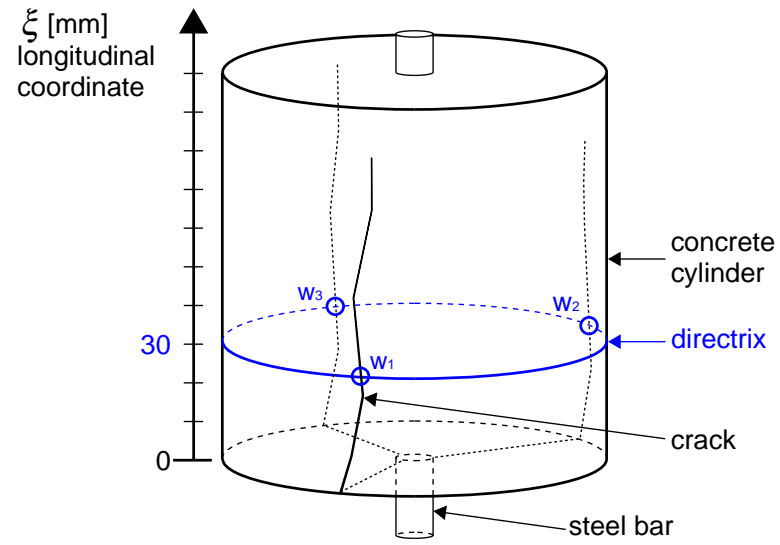

Figure 4. Cumulative crack width on a given directrix

The corrosion products were removed by partially submerging the bars in a $11 \%$ solution of Hydrochloric Acid (HCl) for approximately 16 hours.

After the rust was removed, the bars were weighed and the final mass $m$ compared with the initial mass $m_{0}$ measured before the accelerated corrosion tests. The experimental mass loss is calculated as a difference in bar weight before and after the accelerated corrosion tests:

$$
\Delta m=m-m_{0}
$$

It was assumed that the mass loss occurred homogeneously along the $50 \mathrm{~mm}$ bonded length of the bar $l_{b}$. The mass loss $\Delta m$ can be expressed as a percentage of the initial mass, based on the measured average weight per unit length of the bars $g_{0}$, where:

$$
C_{r}=\frac{\Delta m}{g_{0} \cdot l_{b}} \cdot 100 \%
$$

\section{Results}

The experimental results are hereby presented in terms of measured mass loss and surface crack width.

\subsection{Mass Losses}

Table 3 indicates the average values (calculated on 5 specimens corroded under the same conditions) of the mass loss $C_{r}$ measured at the end of the tests. As will be discussed, severe pitting corrosion was observed in some samples. This effect is also reported in the table, based on visual observations on the maximum pit depth, extent of localisation along the longitudinal axis and variation among bars of the same Series. In the classification, Mild can be related to maximum pit depths of approximately $1.0-2.0 \mathrm{~mm}$, Moderate to $1.5-2.5 \mathrm{~mm}$ and Severe to $2.0-3.0 \mathrm{~mm}$.

\subsection{Crack Widths}

Specimens in Series B exhibited corrosion-induced surface cracking. With the exception of A10-05, specimens in Series A (A10-02, A10-07, A10-15) reached significant levels 
Table 3. Measured mass loss results and observed pitting corrosion

\begin{tabular}{l|clc}
\hline Series & $\begin{array}{c}\text { Average } \\
\text { measured } \\
\text { mass loss } \\
\mathrm{C}_{r}\end{array}$ & (SD) & $\begin{array}{c}\text { Pitting } \\
\text { corrosion }\end{array}$ \\
\hline A10-15 & $24.3 \%$ & $(0.85 \%)$ & Severe \\
A10-07 & $10.3 \%$ & $(0.85 \%)$ & Moderate \\
A10-05 * & $16.9 \%$ & $(0.54 \%)$ & Moderate \\
A10-02 & $5.1 \%$ & $(0.71 \%)$ & Mild \\
\hline B10-08 & $10.2 \%$ & $(3.26 \%)$ & No \\
B10-06 & $8.5 \%$ & $(2.05 \%)$ & Moderate \\
B10-04 & $6.7 \%$ & $(10.46 \%)$ & Moderate \\
B10-03 & $5.1 \%$ & $(1.25 \%)$ & Mild \\
\hline * matunction
\end{tabular}

* malfunction led to $i_{c o r r}>200 \mu \mathrm{A} / \mathrm{cm}^{2}$

of corrosion (up to 24.3\%) without developing visible surface cracks.

As an example of the evolution of the crack width with cylinder height, the cumulative crack width results for specimens B10-08e, B10-06c and B10-04e are shown in Fig. 5. The plot shows that the crack width varied with height and was not uniform. The maximum value typically occurred at the bottom of the cylinders.

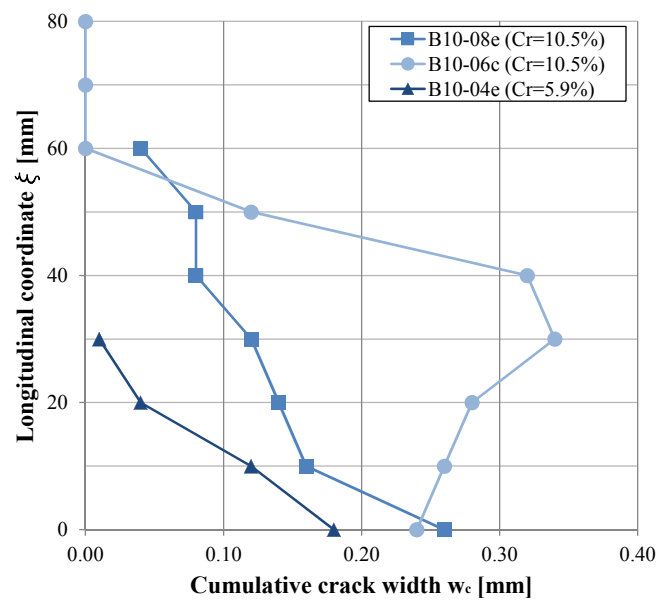

Figure 5. Example of crack width evolution along the cylinder height for three specimens

A summary of the crack width results for each series is presented in Table 4. Where present, the number of cracks on each cylinder also varied, ranging from 1 to 3 . The average number of cracks is also reported, calculated as the average over five specimens corroded under the same conditions.

The results expressed as the maximum cumulative crack width versus degree of corrosion are shown in Fig. 6 The dashed line with triangular markers represent results from Series A. The isolated triangle denotes Series A1005 , where a current density higher than $200 \mu \mathrm{A} / \mathrm{cm}^{2}$ was
Table 4. Crack width results. Average number of cracks is calculated over five specimens corroded under the same conditions. Standard Deviation (SD) in brackets

\begin{tabular}{lc|rc}
\hline Series & $\begin{array}{c}\text { Average } \\
\text { measured } \\
\text { mass loss } \\
\mathrm{C}_{r}\end{array}$ & $\begin{array}{r}\text { Average } \\
\text { no. cracks }\end{array}$ & $\begin{array}{c}\text { Max. cumul. } \\
\text { crack width } \\
\mathrm{W}_{c} \\
{[\mathrm{~mm}]}\end{array}$ \\
\hline $\mathrm{A} 10-15$ & $24.3 \%$ & - & - \\
$\mathrm{A} 10-07$ & $10.3 \%$ & - & - \\
$\mathrm{A} 10-05 *$ & $16.9 \%$ & 2.4 & $0.97(0.30)$ \\
$\mathrm{A} 10-02$ & $5.1 \%$ & - & - \\
\hline $\mathrm{B} 10-08$ & $10.2 \%$ & 2.4 & $0.36(0.16)$ \\
$\mathrm{B} 10-06$ & $8.5 \%$ & 2.0 & $0.19(0.19)$ \\
$\mathrm{B} 10-04$ & $6.7 \%$ & 1.2 & $0.08(0.08)$ \\
B10-03 & $5.1 \%$ & - & - \\
\hline * malfunction led to $i_{\text {corr }}>200 \mu \mathrm{A} / \mathrm{cm}^{2}$ &
\end{tabular}

impressed due to a malfunction in the set-up ${ }^{2}$ The continuous line with circular markers is indicative of the results from Series B, where the bottom face of the specimens was sealed with silicon.

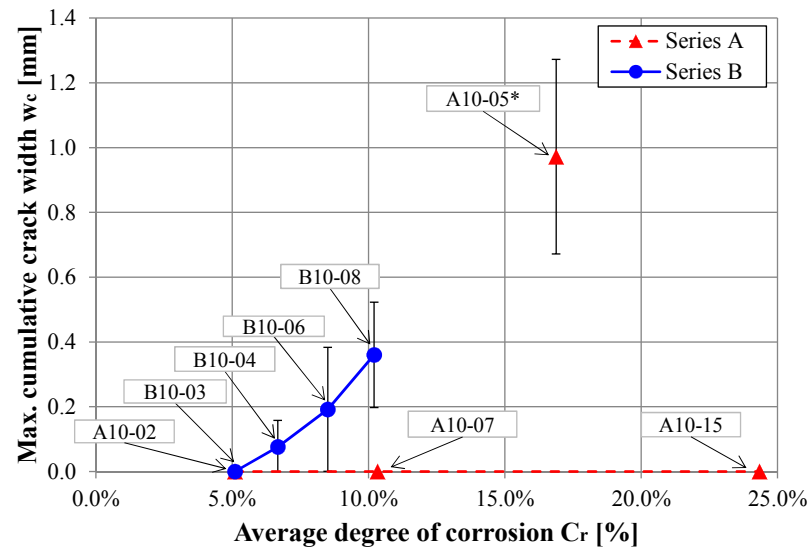

Figure 6. Correlation between maximum cumulative crack width and average degree of corrosion. (* denotes series where malfunction led to $i_{\text {corr }}>200 \mu \mathrm{A} / \mathrm{cm}^{2}$ )

For Series B, the relationship between maximum cumulative crack width and degree of corrosion is almost linear and suggests that a 5.0\% mass loss is the threshold for surface crack appearance under the tested conditions. However, as indicated previously, several specimens in Series A did not exhibit any cracking even after significant mass losses higher than the above mentioned threshold.

\section{Discussion}

Corrosion products occupy a greater volume than the parent metal. If this expansion is confined in a limited volume, expansive pressures build up generating internal stresses.

\footnotetext{
${ }^{2}$ Based on the comparison between measured mass loss and prediction based on Faraday's law, it is plausible that the actual current density impressed on Series A10-05 was between $320-580 \mu \mathrm{A} / \mathrm{cm}^{2}$
} 
Where stresses in the concrete exceed the concrete tensile capacity, the concrete cracks. If expansive pressures can be relieved, cracking may be delayed or not occur at all.

The immersion conditions, exposure to water ingress, presence of chlorides, specimen geometry and debonding sleeves interact to influence whether cracking occurs.

De-oxygenated conditions and presence of chlorides favour localised corrosion [8]. The partial submersion of specimens placed in closed plastic boxes led to conditions of limited oxygen, which caused the development of liquid corrosion products that were free to flow in the interstitial voids between the steel and concrete. It was observed that corrosion products solidified only in the presence of oxygen, after the cylinders were removed from the salt-water bath. This is consistent with observations from other Authors [27], who have reported the development of unstable corrosion products (such as ferrous hydroxide, greenishblack) during the accelerated corrosion phase, attributed to wet concrete and limited oxygen. The same Authors [27] reported the presence of more stable corrosion products of reddish-brown colour after testing, possibly attributed to a drier concrete with more oxygen. The presence of chlorides, even at low concentrations, increases the iron solubility significantly, facilitating the flow of corrosion products within the concrete structure [8, 28]. Beyond a very low threshold of chloride concentrations $(15 \mathrm{mmol} / \mathrm{L})$, the solubility of iron increases by several orders of magnitude [28]. The debonding sleeve represents an artificial void volume and a preferential path for corrosion product to exude from the top flat surface of the cylinders as shown in Fig. 7 and Fig. 8. Leakage of the liquid corrosion products is considered to be a prime reason for not developing significant expansive pressures and subsequent cracking in the majority of specimens from Series A where the bottom face was not sealed. This phenomenon was also observed in Series $\mathrm{B}$, although to a lesser extent as the bottom face was sealed. This represents a limitation in the experimental set-up, especially for short specimens where the sleeved debonded length is not negligible compared to the total length. It was not possible to directly compare results from other authors, as the characteristics of the debonding sleeves are often not included in the published work. In laboratory experiments, the characteristics of the debonding sleeves and seals at their ends have an impact on the results. They therefore need to be considered in the test design, and should be explicitly described in publications.

The expansive stresses due to corrosion are only generated along the bonded length of the reinforcement bar. An unbonded concrete region is often necessary in specimens to be tested under concentric pull-out bond tests, as it avoids parasitic confining effects from the reaction frame, and allows the development of inclined compression struts. However, this adjacent region of 'unstressed' concrete does not build up expansive stresses to the same extent, and it effectively provides a confining action, reducing strains and bridging cracks in the top portion of the concrete cylinder as indicated schematically in Fig. 9. The maximum crack widths are in fact measured at the bottom of the specimens and reduce towards the top, as previously shown in Fig. 5. This represents a limitation of the bond test set-

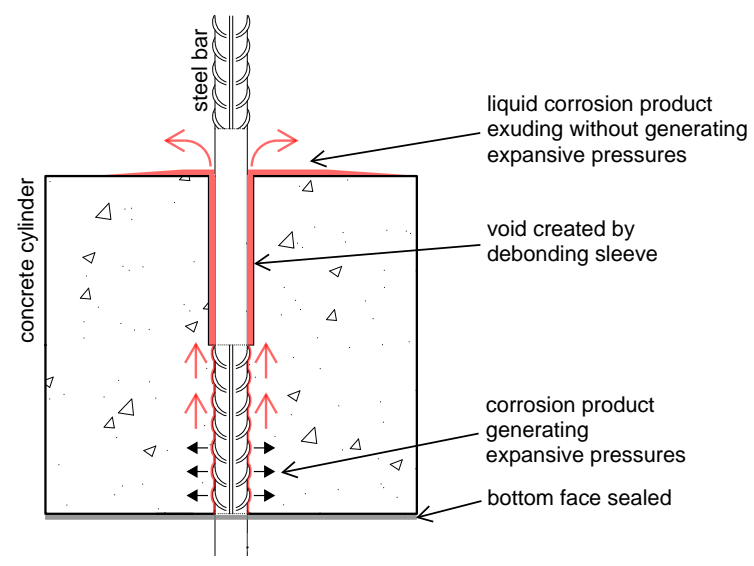

Figure 7. Schematic of corrosion product exuding through debonding sleeve without developing expansive pressures

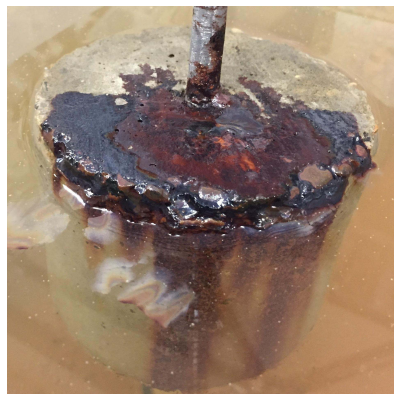

(a)

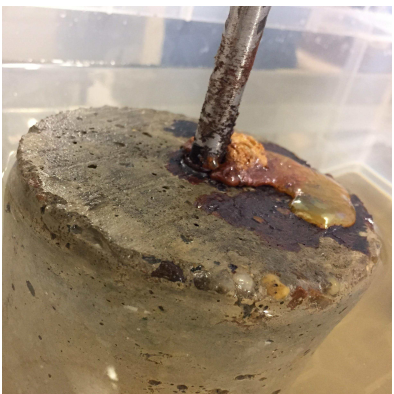

(b)
Figure 8. Photos of corrosion products exuding through the debonding sleeve before precipitation. (a) Specimen B10-06a $\left(\mathrm{C}_{r}=5.2 \%\right)$; (b) Specimen B10-04a $\left(\mathrm{C}_{r}=4.6 \%\right)$

ups intended to capture both corrosion-induced cracking and bond deterioration. Debonding sleeves should be minimised in length and placed symmetrically to provide a more consistent framework to identify corrosion effects.

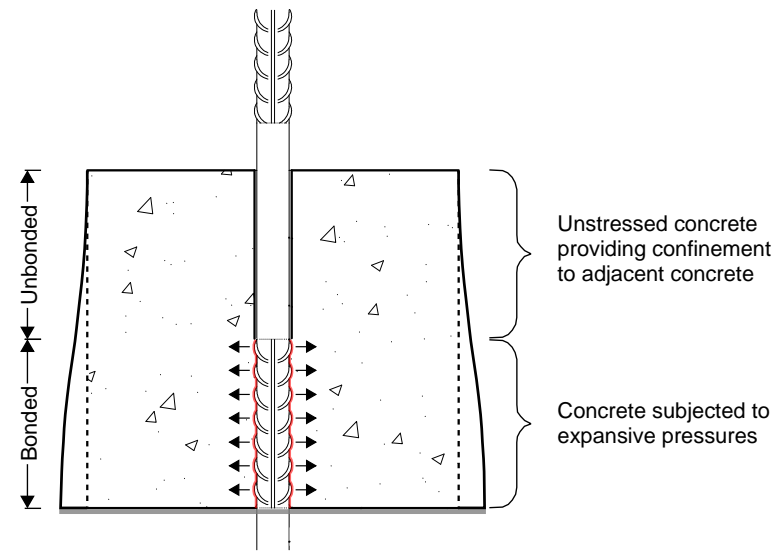

Figure 9. Confining effect provided by unstressed concrete along unbonded length. Indicative elastic deformations under expansive pressures (not to scale)

It is possible that with higher corrosion rates, expansive pressures are developed before the corrosion product 
can flow through the interstitial zone and exude. This effect could justify the behaviour of Series A10-05, where a higher current density was impressed and surface cracks developed.

The exposure to corrosion is not uniform along the bonded length. This can lead to the development of nonuniform corrosion around the bar. This effect was observed in several specimens, especially those of Series A where the bottom face was not sealed. The level of corrosion on the bottom portion of the bars was higher than the top, as shown Fig. 10-a.

In Series B, where the bottom face was sealed and the distribution of current density was more homogeneous along the bar, localised corrosion at the bottom was significantly reduced. However, severe pitting occurred at the top of the cylinders, where corrosion products exuded from the sleeve and stagnated on the flat concrete surface before precipitation. A local reduction in diameter of up to $30 \%$ of the original value was measured in extreme cases, such as in specimen B10-04a shown in Fig. 10. b.

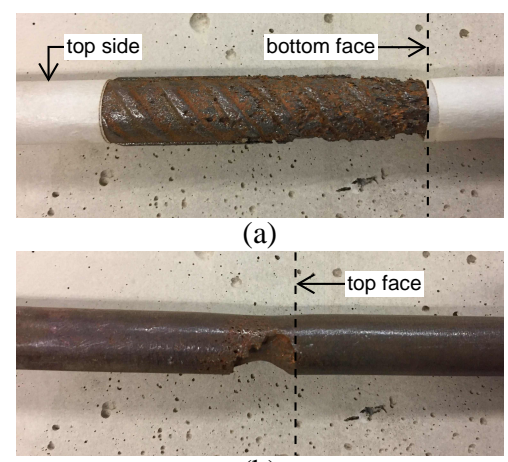

(b)

Figure 10. (a) Localised corrosion on bar at the bottom of specimen A10-15a $\left(\mathrm{C}_{r}=24.9 \%\right)$; (b) Severe pitting corrosion on bar outside the bond length at the top of specimen B10-04a $\left(\mathrm{C}_{r}=4.6 \%\right)$ corresponding to a reduction in diameter to $0.7 \varnothing$

The presence of localised corrosion undermines the validity of average mass loss values. If the mass loss is localised, the average mass loss over the bonded length is less than the calculated value. This could partially explain the absence of surface cracks.

The measured values of mass loss are in many cases higher than the predictions based on Faraday's law. As described by Alonso et al [14], this can be partially explained by the spalling out of the steel, where portions of uncorroded metal are detached due to the oxidisation of the surrounding material. Fig. 11 shows a local reduction in diameter that appears to be due to this effect.

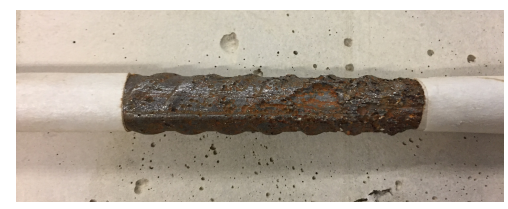

Figure 11. Spalling out of corroded steel on specimen A10-15a
Authors [29-32] have concluded that the orientation of the bar during casting with respect to the direction of gravity has an influence on the characteristics of the 'interfacial transition zone' and the concrete on bottom side of a bar is more porous than elsewhere. Voids in this porous zone would delay the cracking onset. This effect was not replicated in the experiments, as the cylinders are cast and cured with the main axis in the vertical position.

\section{Conclusions}

In reinforced concrete structures, corrosion of the reinforcing steel is often the main cause of structural deterioration that can lead to a reduction in structural capacity. Cracking of the concrete cover is one of the consequences of reinforcement corrosion. This study investigated the correlation between corrosion-induced surface crack width and level of internal corrosion developed under laboratory conditions. Accelerated corrosion was performed using an impressed current of $i_{\text {corr }}=200 \mu \mathrm{A} / \mathrm{cm}^{2}$ on 40 unconfined reinforced concrete cylinders with an embedded steel bar. Average mass losses between 5-24\% were obtained. Where present, corrosion-induced crack widths were measured and correlated to the mass losses. The following conclusions are drawn:

i. Accelerated corrosion testing under conditions of limited oxygen and in the presence of chlorides can lead to the development of liquid corrosion products.

ii. Before solidifying, liquid corrosion products can flow in the voids and interstitial porous structure of the concrete or through the debonding sleeves. They can exude from the specimens reducing the expansive pressures. As a result, corrosion-induced cracking can be delayed or not occur, even for significant levels of corrosion (average mass losses of 24.3\%).

iii. The geometry and configuration of specimens have an influence on the cracking pattern. A specimen design that follows recommendations for bond tests presents challenges if corrosion-induced cracking is also studied: the presence of a debonding sleeve induces a stress-free concrete zone adjacent to the corroded part, which reduces corrosion-induced crack widths.

iv. Accelerated corrosion using an impressed current can lead to non-uniform corrosion along the bar and localised (pitting) corrosion. Hence, average mass loss values are not representative of distributed levels of corrosion. The impact on expansive pressures and other structural consequences must be taken into account in the interpretation of test results.

\section{Acknowledgements}

The authors wish to acknowledge the financial support of the United Kingdom Engineering and Physical Sciences Research Council (EPSRC) via a Doctoral Training Partnership (DTP) award to the University of Cambridge. The 
authors also wish express their gratitude to the staff of the Structures Research Laboratory of the Cambridge University Engineering Department (CUED) for their contributions to the experimental work reported in this publication.

\section{References}

[1] I. Balafas, C. Burgoyne, J. Eng. Mech. ASCE 137, 175 (2011)

[2] M. Davis, N. Hoult, A. Scott, Constr. Build. Mater. 114, 481 (2016)

[3] A. Bossio, G. Lignola, F. Fabbrocino, T. Monetta, A. Prota, F. Bellucci, G. Manfredi, Struct. Concr. 18, 104 (2017)

[4] T.A. El Maaddawy, K. Soudki, J. Mater. Civil Eng. 15, 41 (2003)

[5] K. Bhargava, A. Ghosh, Y. Mori, S. Ramanujam, in 17th Analysis and Computation Specialty Conference - Proceedings. 18-21 May 2006, pp. 302-316

[6] Y. Yuan, Y. Ji, S. Shah, ACI Struct. J. 104, 344 (2007)

[7] B.S. Jang, B.H. Oh, Cem. Concr. Res. 40, 1441 (2010)

[8] U. Angst, B. Elsener, B. Jamali, A. Adey, Mater. Corros. 63, 1069 (2012)

[9] A. Jamali, U. Angst, B. Adey, B. Elsener, Constr. Build. Mater. 42, 225 (2013)

[10] P. Malumbela, G. Moyo, M. Alexander, J. S. Afr. Inst. Civ. Eng. 54, 78 (2012)

[11] A. Cesetti, G. Mancini, Tondolo, in Proceedings of ICCRRR - International Conference on Concrete Repair, Rehabilitation and Retrofitting. 5-8 October 2015, pp. 123-129

[12] fib, fib Bulletin 10 - Bond of Reinforcement in Concrete (fib, 2000)

[13] J. Rodriguez, L. Ortega, J. Casal, J. Diez, in Proceedings of 7th International Conference on Durability of Building Materials and Components (DBMC 7). 19-23 May 1996 (1996), pp. 117-126

[14] C. Alonso, C. Andrade, J. Rodriguez, M. Diez, Mater. Struct. 31, 435 (1998)
[15] A.A. Torres-Acosta, M. Martínez-Madrid, J. Mater. Civil Eng. ASCE 15, 344 (2003)

[16] T. Vidal, A. Castel, R. François, Cem. Concr. Res. 34, 165 (2004)

[17] R. Zhang, A. Castel, R. François, Cem. Concr. Res. 40, 415 (2010)

[18] Y. Zhao, J. Yu, B. Hu, W. Jin, Corros. Sci. 55, 385 (2012)

[19] C. Andrade, A. Cesetti, G. Mancini, F. Tondolo, Struct. Concr. 17, 533 (2016)

[20] G. Mancini, F. Tondolo, Struct. Concr. 15, 408 (2014)

[21] G. Al-Sulaimani, M. Kaleemullah, I. Basunbul, Rasheeduzzafar, ACI Struct. J. 87, 220 (1990)

[22] A. Almusallam, A. Al-Gahtani, A. Aziz, Rasheeduzzafar, Constr. Build. Mater. 10, 123 (1996)

[23] RILEM, RILEM Technical Recommendations for the testing and use of construction materials (RILEM, 1994)

[24] European Committee for Standardisation, EN 123903:2009 Testing hardened concrete-Part 3: Compressive strength of test specimens (CEN, 2009)

[25] European Committee for Standardisation, EN 123906:2009 Testing hardened concrete - Part 6: Tensile splitting strength of test specimens (CEN, 2009)

[26] M. Saifullah, L. Clark, in Proceedings of International Conference: Corrosion and Corrosion Protection of Steel in Concrete. 24-28 July 1994, pp. 591602

[27] P. Malumbela, G. Moyo, M. Alexander, Mater. Struct. 44, 331 (2011)

[28] K. Sagoe-Crentsil, F.P. Glasser, Cem. Concr. Res. 23, 785 (1993)

[29] A. Horne, I. Richardson, R. Brydson, Cem. Concr. Res. 37, 1613 (2007)

[30] T.A. Soylev, R. François, Cem. Concr. Res. 33, 1407 (2003)

[31] U. Angst, Ph.D. Thesis, Norwegian University of Science and Technology (2011)

[32] U. Angst, Ø. Vennesland, C. Larsen, B. Elsener, in Proceedings of the International Congress on Durability of Concrete. 18-21 June 2012 (2012), p. 116 